\title{
The obstinate notion that higher education is a meritocracy
}

\author{
Simpiwe Sobuwa ${ }^{1}$ and Sioux McKenna ${ }^{2}$ \\ ${ }^{1}$ Department of Emergency Medical Care \& Rescue, Faculty of Health Sciences, Durban University of \\ Technology, South Africa \\ ${ }^{2}$ Rhodes University, South Africa \\ Corresponding Author: simpiwes@dut.ac.za
}

(Submitted: 27 May 2019; Accepted: 6 December 2019)

\begin{abstract}
Student success is an enormous concern in light of the high drop-out rates in South African universities. There is a wealth of local and international research which provides complex explanations for these statistics, but the common-sense understanding is that those students who have the right attributes and who work hard will do well. While the notion of higher education as a meritocracy is pervasive, it is invalid given the effects of numerous other mechanisms at play in the students' educational experiences. This article draws from the literature to discuss the problems of the meritocratic explanation in how it fails to sufficiently account for the centrality of agency and the ways in which this intersects with societal structures. We argue that more useful understandings of student success and failure require social theory that acknowledges the complexities underpinning student success or failure.
\end{abstract}

Keywords: higher education, meritocracy, social realism, student success

\section{Introduction}

We live in what has been described as an era of anti-intellectualism and post-truth, where the loudest voices and the simplest explanations gain traction despite the existence of carefully researched nuanced explanations. The dismissal of research is particularly sorely felt by academics who are invested in developing informed understandings of the world around us. But academics are not immune to such matters as we are in and of society and thus as susceptible to problematic assumptions and as likely to bolster unjust structures as anyone else. It is thus perhaps unsurprising that the dominant accounts of student success and failure in higher education held by academics (Case, et al., 2018) are at odds with the wealth of research available. In this article, we problematise the dominant accounts and call for the use of social theory that ensures more complex and credible explanations.

All stakeholders in higher education are directly or indirectly invested in student success. Students may have varied reasons for being in the university but they all hope to graduate with a qualification. Academics and administrators employed in universities are 
also, almost without exception, committed to developing students as successful members of a field who can make a meaningful contribution to society. Despite this, the higher education sector continues to experience problems with retention and throughput (CHE, 2019) and continues to struggle with understanding how and why students drop out or fail to thrive. While there is an enormous body of work researching student learning, much of it is simplistic (Hlengwa, et al., 2018) and even where more sophisticated accounts are available, they are rarely called upon to improve university practice (Niven, 2012), allowing problematic common-sense understandings to thrive (Moyo, 2018). This article makes the case for a social account of learning that foregrounds the agency of students as social beings alongside a consideration of the intersection of such agency with social structures.

\section{Context of high attrition in South Africa}

While student enrolment has grown significantly in South Africa since the advent of democracy, universities continue to struggle with high attrition and low throughput rates (CHE, 2019). The growth in student enrolments has seen an increase in African student enrolments from $68 \%$ in 2011 to $74 \%$ in 2017 . In 2017, the remainder of the student enrolment was made up of $6 \%$ Coloured students, $5 \%$ Indian students, and $16 \%$ White students (CHE, 2019). In the first major cohort analysis, Scott et al. (2007) showed that despite the increased enrolment, there were less impressive changes in relation to student success. Only $30 \%$ of the first-time entering cohort admitted to South African higher education institutions in 2000 had graduated by 2004, with $56 \%$ leaving the original institutions at which they had enrolled without graduating, and $14 \%$ still in the system seven years later (Scott, et al., 2007). Similar findings have emerged in multiple studies since then (Jones, et al., 2008; Letseka and Maile, 2008; Lewin and Mawoyo, 2014).

Of further concern is the fact that African students performed worse than their white counterparts across all fields of study. Thus, the positive gains in terms of African student enrolments appear to have been undermined by retention and throughput rates. Besides the significant financial burden placed on the National Treasury and on individual students by such statistics, there is the human cost of attrition and the ethical obligation on higher education institutions to address these figures. To do so, we need to have a clear understanding of what leads to academic success.

\section{Dominant explanations of academic success}

Academic success is diversely defined in the literature. Cuseo (2007) defines academic success as a holistic phenomenon that comprises various dimensions of personal development and the multiple goals of higher education. Academic success is also defined as 'academic achievement, engagement in educationally purposeful activities, satisfaction, acquisition of desired knowledge, skills and competencies, persistence, attainment of educational outcomes and post-college performance' (York, et al., 2015: 4). While such definitions focus on student learning, the most frequent definition of student success is the 
completion of the undergraduate degree in the expected time (Killen, 1994; Naidoo, 2013). As to what leads to the completion of the degree, the dominant 'everyday' explanation is that students who are 'bright' or hardworking or motivated will be more likely to complete the degree and graduate (Christie, et al., 2007).

This explanation is known as a meritocracy, a term which originated in Michael Young's dystopian novel, The Rise of the Meritocracy (Young, 1958). Young describes a social hierarchy based on educational level and intelligence. Since then, and much to Young's regret (Young, 2001), the term has come to be seen as a positive concept where explanations of how some individuals accrue social reward are that they have more merit rather than that they have privileged positions of class or wealth or some other characteristic. Achieving great wealth or personal status is thus deserved, emerging as it does from the combination of 'IQ plus effort' (Menand, 2019). The meritocracy explanation focuses primarily on the role of inherent attributes and effort in educational attainment in direct contradiction to the literature that suggests other factors play a critical role in student success. It is against this backdrop that this paper seeks to highlight the myth that the South African higher education is in any way a meritocracy.

While it may seem self-evident that students ought to be rewarded on the basis of their abilities and effort, in one of the most unequal countries in the world, students in the South African higher education system have vastly unequal opportunities to achieve the reward of completing a qualification in expected time. The dominance of the belief in a meritocracy in South African higher education has led to what Boughey and McKenna $(2016,2017)$ refer to as 'the discourse of the decontextualised learner' where the student's success or failure is seen to emerge largely or even exclusively as a result of the attributes inherent within her: her intelligence, work ethic, motivation, and other factors. The decontextualised learner account either underestimates or entirely absents the student's beliefs, desires and history. The role of broader societal and institutional structures and cultures are similarly rendered invisible.

An example of this discourse is seen on an annual basis when media publish articles on students 'graduating against all odds' (Case, et al., 2018). These articles highlight students' remarkable achievements through hard work and determination despite the most appalling conditions. While such successes indeed deserve applaud, there is often an undertone to these reports that if a good work ethic paid off for this student, then other students in a similar position can be expected to achieve similarly (Case, et al., 2018). Other examples of such discourses abound in our university corridors where students are regularly deemed to be unmotivated or lazy or to be ill-suited for university education (Case, et al., 2018).

The notion of higher education as a meritocracy continues despite a wealth of literature calling it into question (Alvarado, 2010; Armstrong and Hamilton, 2013; Case, et al., 2018). The dominance of this myth has a number of consequences for the higher education system and for students. For instance, it erodes a student's self-worth because all failure is understood to emerge from a lack of hard work, talent or intelligence. By 'naming' 
the problem as one that emerges from attributes inherent in the student (Boughey, 2002), academics are able to avoid the challenging task of looking to the ways in which our curricula and pedagogy actually serve to exclude. The meritocracy explanation legitimises social inequality by apportioning the cause of student failure solely on the student. Most importantly, the meritocracy explanation of student success suggests that the university and curriculum are neutral with little or no bearing on a student's chances of success. To draw on the myth of meritocracy is to be complicit in social injustice.

Our concern about the extent to which this myth permeates everyday conversations and understandings within the academy is not to deny that students do indeed arrive as individuals with greater or lesser levels of preparedness for higher education. Scott et al. (2007) posit that the lack of academic preparedness for undergraduate programmes is a key reason for the poor student performance in higher education in South Africa. Although apartheid in South Africa ended over two decades ago, the unjust schooling education system still manifests in appalling ways (Govender, 2014).

The lack of quality education in historically and currently disadvantaged schools has resulted in an extreme version of the articulation gap - that is, the mismatch between the exit level from high school and the entry level into university (CHE, 2013; Govender, 2014). Some students struggle to make the transition from a high school environment to a higher education system as they are inadequately prepared in high school. This applies particularly to students from less resourced schools, typically rural or township schools (Jones, et al., 2008; Lewin and Mawoyo, 2014; Scott, et al., 2007). Students may find that the very practices which led to success in school are less useful in a university setting (Case, et al., 2018). Study skills and learning strategies that they acquired in response to the teaching styles and assessment methods at school are often inappropriate in higher education (Lowe and Cook, 2003; Bertram, 2004).

The change from the schooling system to the university system characterised by free time and independence is a difficult transition for all students to make but when they arrive without assumed foundational knowledge, the challenges of the transition are greatly exacerbated and often lead to academic underperformance (Jones, et al., 2008). WilsonStrydom (2012) makes use of the humpback bridge metaphor to reflect on the gap between high school and higher education, stating that the school-leaver is often not able to see across the humpback bridge to the university. While schooling is not designed specifically to prepare students for higher education and only a small percentage of school leavers will ever enter university, it is clear that some schools prepare students better than others.

It would be a mistake, however, to look at schooling on its own to account for the high levels of student attrition and failure in higher education. The practices that may be assumed within the university are multiple and complex and not all can be reduced to issues of school preparedness (Bathmaker, et al., 2016). Many of the practices expected of first year students are those acquired in a range of social, home, and school settings (Armstrong, 2019). These practices or field resources are often termed 'capital' (after the work of Bourdieu) which can be viewed as cultural or social (rather than economic) assets (Clegg, 
2011; Naidoo, 2004). While everybody has cultural and social assets, the form of these differ between societal groups and some are more valued in particular settings than others. Particular cultural or social assets are enablers of academic success in higher education and others are not (Sebidi and Morreira, 2017).

Take, for example, a student from a middle-class home who drives a car to university, owns a laptop with WIFI at home, has meals prepared from home, and whose parents have attended university. It is clear that this student has enormous financial, health, and social network assets. What is perhaps less visible is the extent to which such a student also has access to subtle literacy practices similar to those valued in the higher education sector (Kelly-Laubscher and Van Der Merwe, 2015). While academic language is no-one's mother tongue (Bourdieu and Passeron, 2000), certain higher education practices are more readily acquired by middle class students than those termed working class. Academic language or 'academic literacy' is about more than the technical skills of reading and writing. It includes such practices as approaching a text with scepticism, seeing it as legitimate to take a personal position on a text, and so on. It further includes the varied ways in which students are expected to 'be' in the classroom - actively involved in constructing their own interpretation of the knowledge presented to them while learning how it is that knowledge is constructed in the target discipline (and what 'counts' as acceptable types of claims and valid evidence for such claims within that discipline), actively taking on the gaze on the world valued by the discipline, and so on (Maton, 2013). In myriad ways, the practices expected of students in higher education, which differ significantly across disciplines, are easier for some to take on than for others, most especially when they are never explicitly articulated and are experienced as a set of covert assumptions and expectations.

Bourdieu established that working-class students were less successful not because they were less intelligent than middle-class students (as per the meritocracy account), but because the curriculum was 'biased in favour of those things with which middle-class students were already ex-curricularly familiar' (Robbins, 1993: 153). It is this that leads to the correlations between social class and higher education success evident in every country in the world (Reay and Vincent, 2016; Walpole, 2003). In countries such as South Africa, the issue of social class intersects in complex ways with race, gender, nationality, and other social structures of difference. This raises serious concerns about the role of universities in reinforcing social inequalities.

As universities around the world have massified, so the student body is no longer even slightly homogenous and this has implications for teaching and learning. While the focus of much South African research on this issue has been the underprepared nature of the student, there have been many who have asked about the underpreparedness of the university to attend to the needs and recognise the values of a more diverse student body (Dhunpath and Vithal, 2012). And even back in 1985, Vilakazi and Tema were raising this question. Thomas et al. (2002) argue that curricula and pedagogy that fail to take the social practices and prior knowledge of students into account are doomed to fail. 
While students from a less privileged background might not drive a car to university, own a laptop or have sufficient food to eat, nor have as ready access to the literacy practices typically valued by the university, Yosso (2005) asserts that these students have access to community cultural wealth. This 'bonding' capital can encourage resilience by inspiring them to stay put in the face of adversity. The extent to which the university acknowledges this capital and builds it into the student experience is generally very limited, however (Clegg, 2011). Connecting to students' prior knowledge and recognising other ways of being in the world is key to nurturing epistemological access; however, it does more than that, it opens the possibility for powerful knowledge from outside of the academy to make its way into the curriculum.

In addition to, and to some extent linked to the issue of literacy practices of the academy, are linguistic challenges experienced by students in higher education. The language of instruction in South African higher education institutions is still either English or Afrikaans and this often creates a barrier for many students who do not have these languages as their home language. However, it would be a mistake to conflate proficiency with language as the medium of instruction with access to the literacy practices of the discipline. Various studies have shown how middle-class students with strong schooling backgrounds enjoy far greater levels of higher education success even where they have very low levels of proficiency in the medium of instruction (Sullivan, 2001; Weddington, 2010). Conversely, studies over the years have shown that students' social class correlates to their higher education success even where the whole student body shares the medium of instruction as their home language (Sullivan, 2001; Weddington, 2010).

\section{The need for strong theory}

Despite the availability of more powerful explanations, the dominant everyday account of student success remains that of a meritocracy. We seem to prefer straightforward causal accounts of student success, even though sociologists have long argued for more nuanced explanations of all social events. What is needed are accounts that allow us to make sense of the role of the structures and cultures of society and the agency that individuals bring into this context.

Such accounts are not hard to come by. Over the years, a wealth of research has been developed within South Africa and further afield to provide more generative lenses on student success and failure. Many of these have drawn from feminist theory to show how race, ethnicity, home language, sexuality, gender and so on intersect to shape how students engage with the social context of the university. Leibowitz and Bozalek have worked with various other academics in South Africa to look at the extent to which assumptions within higher education lead to social injustices (Leibowitz \& Bozalek, 2016). Their work draws on and extends Fraser's calls for recognition, representation, and redistribution if we are to achieve parity of participation within higher education and other social spaces (Fraser, 1995; $1999 ; 2001)$. Much of their work, and that of others researching in this area in South Africa, also draws from and collaborates with that of Zembylas and others (for example: Zembylas, 
et al., 2014; Zembylas, 2015). The very active 'University of the Western Cape group' comprising Bozalek and a number of others such as Shefer, Carolissen, Clowes, and Ngabaza (for example: Leibowitz, et al., 2010; Shefer, et al., 2018) use a range of theoretical lenses to show how the knowledge practices of the discipline are mediated by a range of identities of both the student and the institution. At the University of KwaZulu-Natal, we have Msibi (for example: Msibi, 2013, 2016; Msibi and Jagessar, 2015) and others using queer theory to challenge the idea of the decontextualised learner succeeding or failing on their own merit. At the University of Free State, Walker and colleagues have developed Sen's capabilities work (for example: Walker and Wilson-Strydom, 2017; Walker, 2018) to call for richer accounts of how it is that some students flourish while others fail to thrive. And at the University of Cape Town, Luckett, Shay and others (for example: Luckett and Hunma, 2014; Luckett and Shay, 2017) have drawn on Legitimation Code Theory and Critical and Social Realism to develop similarly rich accounts. They have been particularly clear on articulating how the structure of the target knowledge itself acts as a constraint (or enablement) of student learning.

We are thus not without a range of powerful theoretical lenses that will allow us to better understand the processes of student success and failure, but as Niven (2012) and others have shown (for example, Moyo, 2018; Hlengwa, et al., 2018), this scholarship of teaching and learning has failed to achieve much traction within the university itself.

Many have found Archer's social realist account to be very useful in pushing us to consider more complex understandings of students' success and failure in the university. In the rest of this article we provide a brief overview of how this theory challenges the dominant meritocracy account. We are not here proselytising for this particular approach - what we are calling for are theoretical approaches that insist on an understanding of the varied roles played by both social structures and student agency.

\section{Social realism as a challenge to the meritocratic account}

Higher education institutions have traditions, values, beliefs and ideas that shape their identity - these take the form of structural and cultural systems (Monnapula-Mapesela, 2017). Archer's theory of human agency (1995) argues that people (agents) interact with the parts (structural and cultural systems) in a process she refers to as socio-cultural and structural interactions. Archer (1995) views structure, culture and agency as entities that each possess causal powers with structural emergent properties such as institutional structures, cultural emergent properties, such as beliefs and values, and people emergent properties, such as actors and agents, with emergent properties of an individual differing from that of an organised group. Archer defines primary agents as collectivities that share the same life chances who are involuntarily born into a socially stratified system. Students who find themselves within the constraints of the structural and cultural system of the university may reflect on their position and feel constrained by the norms, values, expectations and practices that surround them. They may find them overwhelming and alienating, especially as many of them will not be made explicit. As primary agents, these 
students may realise that they are severely limited in their power to transform such structural or cultural conditions. They may then take on what Archer terms corporate agency. An example of students engaged as corporate agents was witnessed during the \#FeesMustFall movement when students collectively sought to transform the structural and cultural system of higher education which they deemed unjust.

Higher education institutions and disciplines are not neutral, they emerge as structures and cultures over the years, and while a long history may make them resilient, they are not monolithic. University structures and cultures shift in response to the agency of those who interact with them and in response to the structural and cultural systems outside of the university. The intersection of the university's various social and cultural systems and the student's agency can thus either constrain or enable her from achieving her personal project in multiple ways. In other words, agents are shaped by the systems in which they find themselves and they interact to produce intended or unintended consequences that can lead to the systems being transformed. Accordingly, the social structure and institutional culture play a significant role in enabling or constraining student outcomes (Case, et al., 2018).

The dominant account of student success as a meritocracy fails to provide such a nuanced account of agency thereby undermining the student's role in understanding and creating new knowledge (Luckett and Luckett, 2009). The meritocracy account of agency suggests that students are seen to either have enough of the required attributes in some pre-determined way or to lack what is required.

Yorke and Longden (2004) assert that a key component of academic success is students perceiving themselves as agents of their own learning. Likewise, Morrow (2009) indicates that epistemological access is not something that can be done to the student but rather something that requires active engagement by the student. Ontological assumptions have a direct impact on the construction of the learning contexts and processes (Luckett and Luckett, 2009). In other words, the ways in which we construct knowledge is related to our sense of being (McKenna, 2012). If the culture of the institution seems contradictory to the personal project of the individual student and this is not mediated to ensure complementarity, it is unlikely that she will have the freedom to act towards her own success.

\section{Agency in a Social Realist lens}

Agency in social realism is synonymous with causality (Hartwig, 2007) in that it focuses on the individual's freedom to act. Furthermore, agency is intentional. For example, a student unfamiliar with the literacy practices of the discipline may copy texts from elsewhere thereby using their agency to improve their writing abilities, albeit in a manner deemed unacceptable to the academy. Also, agency is irreducible. In other words, one has no choice but to exercise their agency. That is, even if one chooses to abstain from exercising agency, this is still a choice and thus an action (Bhaskar, 2002). Thus, every decision that one takes, is a choice and an action, thereby an exercise of agency. But we are not entirely free in making choices and undertaking actions. 
The dominant meritocracy accounts of student learning place responsibility for success at students' feet without recognising the constraints within which they are working and without seeing the development of agency of the student as central to the academic project. This leads to a reductive account which fails to acknowledge both the identity work involved in the learning process, which is oftentimes emotionally alienating, and the social context within which learning takes place.

As 'primary agents', students generally hold little institutional power to articulate the ways in which institutional structures and cultures might constrain their agency. It is up to those of us with institutional power, 'social actors', to create spaces for such articulation and to reflect on how the structures and cultures might foster agency in powerful ways. Those academic staff engaged in curriculum development, teaching, or assessment have a responsibility to consider the ways in which institutional practices may be enabling or constraining student agency.

Based on the complex relationship between structures, cultures, and agency we have presented, we propose the following definition of academic success, namely, the emergence of student agency to achieve the epistemological access necessary to complete the qualification. The emergence of agency would require tackling 'ontological absences'. Absences can be 'undesirable things' that act as constraints or the simple non-existence of an entity (Bhaskar, 1993). Thus, agency needs to be nurtured which can grapple with any ontological absences in the curriculum whereby students' sense of self and personal projects are not made invisible. Such agency would enable both the acquisition of and the challenging of the target knowledge. Such agency to acquire and, where necessary, challenge the target knowledge is equally important to be evidenced in academics. Luckett and Luckett (2009: 469) argue that developing 'a sense of personal identity and social agency is a pre-condition for succeeding academically and developing a professional identity'.

Our definition improves on other definitions of student success because it recognises student agency and it shows how such agency intersects with context. It acknowledges that there are both epistemic and ontological challenges that students have to overcome to achieve academic success and thus student failure is not simply a lack of inherent abilities but rather emerges from the interplay of multiple mechanisms, each of which have causal powers. While the more common sense explanations for the emergence of student success or failure, such as student motivation, intelligence, and language proficiency, may well be worth considering, they need to be placed within a far more sophisticated analysis. Taking on a social theory of student success requires a more nuanced account which would include the roles played by the student's context, the history of the institution, the nature of the field, and so on.

Taking on some form of social account of student learning prevents us from simplistic explanations that place the explanations for student failure solely on the students' shoulders. It forces us to look at how students' experiences and expectations interact with those of the university. It makes us ask questions about who is being included and excluded and it helps 
us to make sense of the ways in which the university can unwittingly perpetuate social divisions. This has enormous implications for pedagogy whereby making the norms and values of the discipline explicit and open to critique becomes a central requirement. Crucially, this also entails asking questions about the extent to which the curriculum is by its nature transformative. Such questions require 'adjusting the scale of the problem [and] interrogating assumptions informing the norms of the curriculum' (Luckett and Shay, 2017: 1). Furthermore, it is the development of student agency that becomes the shared goal.

\section{Conclusion}

This paper argues against the dominant conception of higher education as a meritocracy, which sees student success or lack thereof to be a result of the students' inherent abilities. The belief in education as a meritocracy fails to take student agency into account nor does it consider the role of multiple structural and cultural mechanisms in enabling or constraining success. In particular, the notion of education as a meritocracy allows us to ignore how our educational practices privilege students who come from middle-class backgrounds. This absolves the university from reflecting on the extent to which it is a cultural, social and political space which can enable or constrain student agency.

We have shown that there are a number of theoretical approaches that would ensure that we look beyond the common sense explanations and come to a fuller understanding of student success and failure. While the Humanities and Social Sciences are notorious for fighting bitterly over competing theories, we suggest that any strong social theory that demands a consideration of the intersections between social structures, institutional cultures, and the development and enactment of student agency will go a long way towards producing better understandings of higher education.

We outlined one such approach. Social realism considers that there are myriad epistemic and ontological challenges that students have to overcome to succeed in higher education, and they have to do so within the complexities of their own histories and within the structures and cultures of the institutions in which they study. Ultimately, we need explanations of student success that foreground both student agency and the role of social structures. Such explanations are readily available to us in the South African literature, but we need to draw on them more explicitly in our day to day work in the academy.

\section{Author Biographies}

Simpiwe Sobuwa is the Department Head of the Emergency Medical Care \& Rescue at the Durban University of Technology. $\mathrm{He}$ is also the postgraduate coordinator of the Department. His research interests focus on emergency care education and the enablers and barriers to academic success in emergency care.

Sioux Mckenna is the Director of the Centre for Postgraduate Studies at Rhodes University where she also manages a large $\mathrm{PhD}$ programme. She is the programme manager of a number of international projects focused on the development of research-rich environments. 


\section{References}

Alvarado, L. 2010. Dispelling the meritocracy myth: Lessons for higher education and student affairs educators. The Vermont Connection, 31: 10-20.

Archer, M.S. 1995. Realist Social Theory: The Morphogenetic Approach. Cambridge: Cambridge University Press.

Armstrong, E. A. \& Hamilton, L. T. 2013. Paying for the Party: How College Maintains Inequality. Cambridge, MA: Harvard University Press.

Armstrong, M. 2019. Learning to learn: A critical realist exploration into the home established learning practices of a marginalised community in Port Elizabeth. Unpublished Doctoral Thesis, Rhodes University.

Bathmaker, A.-M, Ingram, N., Abrahams, J., Hoare, A., Waller, R. \& Bradley, H. 2016. Higher Education, Social Class and Social Mobility: The Degree Generation. London: Palgrave McMillan.

Bertram, C. 2004. Exploring informal student study groups in a South African teacher education programme. In Mills, R. \& Tait, A. (eds.) Rethinking Learner Support in Distance Education. London: Routledge.

Bhaskar, R. 1993. Dialectic: The Pulse of Freedom. London: Verso.

Bhaskar, R. 2002. Reflections on Meta-Reality: Transcendence, Emancipation and Everyday Life. New Delhi: Sage.

Boughey, C. 2002. 'Naming' students' problems: An analysis of language related discourses at a South African university. Teaching in Higher Education, 7(3): 295-307.

Boughey, C. \& McKenna, S. 2016. Academic literacy and the decontextualised learner. Critical Studies in Teaching \& Learning, 4(1): 1-9.

Boughey, C. \& McKenna, S. 2017. Analysing an audit cycle: A critical realist account. Studies in Higher Education, 42(6): 963-975.

Bourdieu, P. \& Passeron, J. 2000. Reproduction in Education, Society and Culture. London: Sage.

Case, J.M., Marshall, D., McKenna, S. \& Mogashana, D. 2018. Going to University: The Influence of Higher Education on the Lives of Young South Africans. Cape Town: African Minds.

Christie, H., Tett, L., Cree, V. E., Hounsell, J. \& McCune, V. 2007. 'A real rollercoaster of confidence and emotions': Learning to be a university student. Studies in Higher Education, 33(5): 567-581.

Clegg, S. 2011. Cultural capital and agency: connecting critique and curriculum in higher education. British Journal of Sociology of Education, 32(1): 93-108.

Council on Higher Education (CHE). 2013. A proposal for undergraduate curriculum reform in South Africa: The case for a flexible curriculum structure. Pretoria. Available at: https://www.che.ac.za/sites/default/files/publications/Full_Report.pdf (accessed 22 March 2019). 
Council on Higher Education (CHE). 2019. Vital Stats: Public Higher Education 2017. Pretoria. Available at:

https://www.che.ac.za/sites/default/files/publications/VitalStats $\% 20$ -

\%20Public\%20Higher\%20Education\%202017.pdf (accessed 01 May 2019).

Cuseo, J. 2007. Student success: Definition, outcome, principles and practices. An excerpt from 'The Big Picture' an resource for college transitions. Marymount College, University of South Carolina.

Dhunpath, R. \& Vithal R. 2012. Alternative Access to Higher Education: Underprepared Students or Underprepared Institutions? Cape Town: Pearson.

Fraser, N. 1995. From redistribution to recognition? Dilemmas of justice in a 'post-socialist' age. New Left Review, 212: 68-93.

Fraser, N. 1999. Social justice in the age of identity politics: Recognition, and participation. In Ray, L. \& Sayer, A. (eds.) Culture and Economy After the Cultural Turn and Economy After the Cultural Turn. London: Sage Publications.

Fraser, N. 2001. Recognition with Ethics? Theory, Culture \& Society, 18(2-3): 21-42.

Govender, S.D. 2014. Students' construction of academic success in higher education. Unpublished Doctoral Thesis, University KwaZulu-Natal.

Hartwig, M. 2007. Dictionary of Critical Realism. London: Routledge.

Hlengwa, A., McKenna, S. \& Njovane, T. 2018. The lenses we use to research student experiences. In Ashwin, P. \& Case, J. (eds.) Pathways to the Public Good: Access, Experiences and Outcomes of South African Undergraduate Education. Cape Town: African Minds.

Jones, B., Coetzee, G., Bailey, T. \& Wickham, S. 2008. Factors that facilitate success for disadvantaged higher education students: An Investigation into approaches used by REAP, NSFAS and selected higher education institutions. Cape Town.

Kelly-Laubscher, R. \& Van Der Merwe, M. 2015. An intervention to improve academic literacies in a first-year university biology course. Critical Studies in Teaching and Learning, 2(2): 1-23.

Killen, R. 1994. Differences between students' and lecturers' perceptions of factors influencing students' academic success ta university. Higher Education Research \& Development, 13(2): 199-211.

Letseka, M. \& Maile, S. 2008. High university drop-out rates: A threat to South Africa's future. Available at:

http://www.hsrc.ac.za/uploads/pageContent/1088/Dropout\%20rates.pdf. (accessed 22 March 2019).

Lewin, T. \& Mawoyo, M. 2014. Student Access and Success: Issues and Interventions in South African Universities. Cape Town.

Leibowitz, B., Bozalek, V., Carolissen, R., Nicholls, L., Rohleder, P. \& Swartz, L. 2010. Bringing the social into pedagogy: Unsafe learning in an uncertain world. Teaching in Higher Education, 15(2): 123-133. 
Leibowitz, B. \& Bozalek, V. 2016. The scholarship of teaching and learning from a social justice perspective. Teaching in Higher Education, 21(2): 109-122

Lowe, H. \& Cook, A. 2003. Mind the gap: Are students prepared for higher education? Journal of Further and Higher Education, 27(1): 53-76.

Luckett, K. \& Luckett, T. 2009. The development of agency in first generation learners in higher education: a social realist analysis. Teaching in Higher Education, 14(5): 469481.

Luckett, K. \& Hunma, A. 2014. Making gazes explicit: facilitating epistemic access in the Humanities. Higher Education, 67(2): 183-198.

Luckett, K. \& Shay, S. 2017. Reframing the curriculum: a transformative approach. Critical Studies in Education, Online First, 1-16. DOI: 10.1080/17508487.2017.1356341.

Maton, K. 2013. Making semantic waves: A key to cumulative knowledge building. Linguistics and Education, 24(1): 8-22

Menand, L. 2019. Is meritocracy making everyone miserable? The New Yorker. Available at: https://www.newyorker.com/magazine/2019/09/30/is-meritocracy-making-everyonemiserable. (accessed 20 October 2019).

McKenna, S. 2012. The context of access and foundation provisioning in South Africa. In Dhunpath, R. \& Vithal, R. (eds.) 2012. Alternative Access to Higher Education: Underprepared Students or Underprepared Institutions? Cape Town: Pearson Education South Africa.

Monnapula-Mapesela, M. 2017. Developing as an academic leader in a university of Technology in South Africa: Dealing with enabling and constraining teaching and learning environments. Critical Studies in Teaching \& Learning, 5(2): 69-85.

Morrow, W. 2009. Bounds of Democracy: Epistemological Access in Higher Education. Pretoria: Human Sciences Research Council Press.

Moyo, T. 2018. An analysis of the implementation of the Teaching Development Grant in the South African Higher Education Sector. Unpublished Doctoral Thesis, Rhodes University.

Msibi, T. 2013. Queering transformation in higher education. Perspectives in Education, 31(2): 65-73.

Msibi, T. \& Jagessar, V. 2015. Restricted freedom: Negotiating same-sex identifications in the residential spaces of a South African university. Higher Education Research \& Development, 34(4): 750-762.

Msibi, T. 2016. Queering Curriculum Studies in South Africa. In Samuel, M.A, Dhunpath, R. \& Amin, N. (eds.) Disrupting Higher Education Curriculum. Constructing Knowledge: Curriculum Studies in Action. Rotterdam, SensePublishers.

Naidoo, R. 2004. Fields and institutional strategy: Bourdieu on the relationship between higher education, inequality and society. British Journal of Sociology of Education, 25(4): 457-471. 
Naidoo, P., Motala, N. \& Joubert, R. 2013. Matriculation scores as an indicator of academic success in an occupational therapy education programme. South African Journal of Occupational Therapy, 43(1): 21-25.

Niven, P.M. 2012. Narrating emergence in the curious domain of academic development research: a realist perspective. Unpublished Doctoral Thesis, Rhodes University.

Reay, D. \& Vincent, C. 2016. Theorizing Social Class and Education. London: Routledge.

Robbins, D. 1993. The practical importance of Bourdieu's analyses of higher education. Studies in Higher Education, 18(2): 151-63.

Shefer, T., Strebel, A., Ngabaza, \& Clowes, L. 2018. Student accounts of space and safety at a South African university: implications for social identities and diversity. South African Journal of Psychology, 48(1): 61-72.

Scott, I., Yeld, N. \& Hendry, J. 2007. Higher Education Monitor 6: A case for improving teaching and learning in South African Higher Education. Pretoria.

Sebidi, K. \& Morreira, S. 2017. Accessing powerful knowledge: A comparative study of two first year sociology courses in a South African university. Critical Studies in Teaching \& Learning, 5(2): 33-50.

Sullivan, A. 2001. Cultural capital and educational attainment. Sociology, 35(4): 893-912.

Thomas, L., Quinn, J., Slack, K., Casey, L. 2002. Student Services: Effective Approaches to Retaining Students in Higher Education. Staffordshire: Institute for Access Studies, Staffordshire University.

Vilakazi, H. \& Tema, B. 1985. White universities and the black revolution. ASPects:, 6: 1840.

Walker, M. \& Wilson-Strydom, M. 2017. Socially Just Pedagogies, Capabilities and Quality in Higher Education. New York, Palgrave.

Walker, M. 2018. Dimensions of higher education and the public good in South Africa. Higher Education, 76(3): 555-569.

Walpole, M. 2003. Socioeconomic status and college: How SES affects college experiences and outcomes. The Review of Higher Education, 27(1): 45-73.

Weddington, G. 2010. It's not the language: alternative explanations of the education gap for African American Children. Topics in Language Disorders, 30(1): 48-56.

Wilson-Strydom, M. 2012. A framework for facilitating the transition from school to university in South Africa: a capabilities approach. Unpublished Doctoral Thesis, University of the Free State.

Young, M. 1958. The rise of the meritocracy. Penguin. Qualitative Research in Education, $1(2)$, p.133

Young, M. 2001. Down with meritocracy. The Guardian, 29(6): 1

Yorke, M. \& Longden, B. 2004. Retention and Student Success in Higher Education. Maidenhead: Society for Research in Higher Education and Open University Press.

York, T., Gibson, C. \& Rankin, S. 2015. Defining and measuring academic success. Practical Assessment, Research \& Evaluation Electronic Journal, 20(5): 1-20. 
Yosso, T. 2005. Whose culture has capital? A critical race theory discussion of community wealth. Race Ethnicity and Education, 8(1): 69-91.

Zembylas, M. 2015. Pedagogy of discomfort and its ethical implications: The tensions of ethical violence in social justice education. Ethics and Education, 10(2): 163-174.

Zembylas, M. \& Bozalek, V. \& Shefer, T. 2014. Tronto's notion of privileged irresponsibility and the reconceptualisation of care: Implications for critical pedagogies of emotion in higher education. Gender and education, 26(3): 200-214. 